\title{
The future of preventing and treating Nipah virus infection
}

\author{
"Recently, the WHO has declared Nipah virus to be a priority pathogen, \\ and the Coalition for Epidemic Preparedness Innovations is therefore \\ focusing on Nipah virus together with Middle East respiratory \\ syndrome coronavirus and Lassa virus as their first disease targets."
}

Keywords: infectious diseases $\bullet$ neglected diseases $\bullet$ Nipah virus $\bullet$ paramyxovirus $\bullet$ vaccines

First draft submitted: 29 April 2017; Accepted for publication: 11 May 2017; Published online: 8 August 2017

\begin{abstract}
Nipah virus $(\mathrm{NiV})$ is a recently emerged paramyxovirus that causes meningoencephalitis, severe respiratory distress and systemic vasculitis in humans with outbreak mortality rates ranging from 38 to $92 \%[1]$ and survivors frequently suffering from long-term neurological sequelae [2]. NiV was discovered in 1998 and has been responsible for nearly annual outbreaks throughout Southeast Asia. Fruit bats from the genus Pteropus (flying foxes) serve as the host for NiV in nature, and they can transmit the virus to humans through intermediate livestock hosts [3] or through contaminated date palm sap [4,5] followed by human-to-human transmission [6]. Advances in understanding the pathogenesis of $\mathrm{NiV}$ have occurred in the two decades since $\mathrm{NiV}$ was discovered [1,7-13], but little progress has been made in terms of preventing and treating human infections. This should be the focus of $\mathrm{NiV}$ research in the coming decade with three areas of synergizing emphasis: prevention through vaccination; prevention through modifying risk factors; and the development of therapeutics and techniques capable of treating patients currently infected to reduce morbidity and mortality.
\end{abstract}

\section{Prevention through vaccination}

Prevention through vaccination certainly includes human vaccination in endemic areas but also includes vaccinating livestock animals, particularly pigs and perhaps horses in certain endemic areas [14]. While livestock vaccination would not prevent outbreaks of $\mathrm{NiV}$ in areas where it is primarily spread through date palm sap contamination, there are regions where this method could be quite effective, if it could be made cost effective. However, most efforts are being directed toward human vaccination.

The academic community of scientists has produced a number of vaccine candidates capable of complete protection against $\mathrm{NiV}$ disease in preclinical studies of multiple small animal and nonhuman primate models [15]. These candidates include subunit and vectored vaccine platforms. Candidates using a vesicular stomatitis virus vector are the most advanced having demonstrated protection in hamsters, ferrets and African green monkeys. The academic community is unlikely to be able to fund human clinical trials of these vaccines and the pharmaceutical industry traditionally has been reluctant to fund research and development of vaccines for diseases with limited incidence, albeit with devastating pandemic potential. However, following the Ebola outbreak of 2014 it became clear that a new paradigm was needed. Thankfully, a new international coalition of governments and pharmaceutical companies called the Coalition for Epidemic Preparedness Innovations (CEPI) was formed in January 2017 to develop safe,

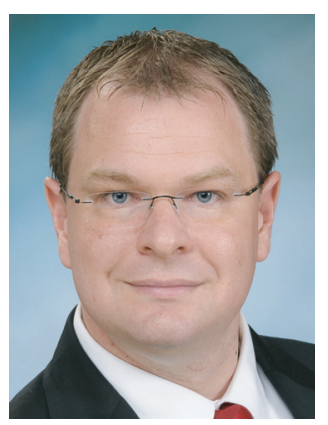

Benjamin A Satterfield Department of Microbiology \& Immunology, University of Texas Medical Branch, 301 University Blvd, Galveston, TX 77598, USA:

Department of Medicine, Mayo Clinic, 200 First Street, SW, Rochester, MN 55905, USA;

satterfield.benjamin@mayo.edu 
effective and affordable vaccines for diseases with pandemic potential, such as $\mathrm{NiV}$ [16].

Recently, the WHO has declared NiV to be a priority pathogen, and CEPI is therefore focusing on $\mathrm{NiV}$ together with Middle East respiratory syndrome coronavirus and Lassa virus as their first disease targets. Building off previous work in the academic community, they aim to have two new experimental vaccines ready for each of these diseases beginning phase I clinical trials within 5 years so that they will be in place for efficacy studies in the event of continued or large outbreaks [16]. It will be due to paradigm shifts, like the creation of CEPI and, hopefully, other forthcoming organizational innovations, that will finally allow for the prevention of emerging infectious diseases including NiV.

\section{Prevention through modifying risk factors}

Preventing humans from being infected through nonvaccination efforts will perhaps play an even more important, and less expensive, role in controlling $\mathrm{NiV}$ disease. These efforts fall into two broad categories depending on the local epidemiology. In regions where livestock act as an intermediate host, preventing animals from coming into contact with $\mathrm{NiV}$ is relatively straightforward and involves keeping bat roosting trees and fruit trees away from areas of susceptible livestock farms and pastures. This effort has already been largely effective in some areas including Malaysia.

In regions where the primary source is contaminated date palm sap, this is a trickier endeavor as it involves alterations in human behavior. In Bangladesh, date palm sap is collected from taps overnight, and infrared cameras have found nocturnal evidence of these bats drinking from, and urinating and defecating in, the open jars collecting date palm sap [17]. Efforts to modify the human behaviors and prevent NiV infection in these regions are already underway and, if given sufficient resources and support, they are likely to lead to a drastic decrease in incidence of $\mathrm{NiV}$ outbreaks. These efforts include campaigns to increase awareness of $\mathrm{NiV}$ disease and its source through written, radio and televised means; using inexpensive and often locally produced tree skirts to prevent bats from access-

"It will be due to paradigm shifts, like the creation of the Coalition for Epidemic Prepared-

ness Innovations and, hopefully, other forth-

coming organizational innovations, that will

finally allow for the prevention of emerging

infectious diseases including Nipah virus.

ing the collection jars; and encouraging the boiling or pasteurization of date palm sap before consumption as this inactivates $\mathrm{NiV}[18,19]$. Overall, these efforts have so far met with success where implemented; however, implementation has proved difficult in many regions due to traditional cultural practices.

With climate change and human encroachment into flying fox habitats, it is likely that outbreaks will begin to occur in regions that have not yet experienced $\mathrm{NiV}$ outbreaks. Therefore, prevention methods will have to be adapted to the new local cultures and the importance of having a vaccine available will be even further underscored for containment in these new regions.

\section{Development of therapeutics \& treatment modalities}

Although prevention is the best option for any infectious disease, once an outbreak has begun, the impor-

"With climate change and human encroachment into flying fox habitats, it is likely that outbreaks will begin to occur in regions that have not yet experienced NiV outbreaks."

tance of having therapeutics and treatment modalities becomes essential. With CEPI moving vaccine candidates forward to clinical trials, the discovery of new therapeutics and targets is the area where academic science is likely to be of great help over the next decade. Only limited work has been done in this area, with monoclonal antibodies being the most advanced in preclinical studies; however, antibody-based drugs tend to be quite expensive and are very disease specific. In addition to furthering the antibody therapeutic studies, future progress should focus on siRNAs, smallmolecule drugs, the screening of currently approved drugs for NiV efficacy and, most especially, identifying broad-spectrum antivirals. The basic science work has already begun to identify novel targets for future drug development including viral protein motifs, viral RNAs, host proteins involved in antiviral responses and proteins hijacked by $\mathrm{NiV}$, as well as host RNA targets. The ability to target host proteins or RNAs has the advantage of making resistance development much more difficult and is much more likely to offer potential for broad-spectrum antiviral activity as these pathways are often utilized by many different viruses.

The last 5 years have shown light on the importance of the NiV Matrix protein, Phosphoprotein, and the accessory proteins $\mathrm{V}, \mathrm{W}$ and $\mathrm{C}$ in the pathogenesis of $\mathrm{NiV}$ in small animal models $[1,7-9,12]$. Studies in the near future will confirm if these interactions are also important in pathogenesis in nonhuman primates. These will likely be the important viral targets, along with the outer membrane Glycoprotein and Fusion protein, for novel drug development. In addition, studies in the near future will also further characterize the interactions between these $\mathrm{NiV}$ proteins and 
specific host proteins to identify the exact viral motifs and/or host protein motifs to target in future drug development.

An additional area of importance that will shine light on human immune factors that can protect against $\mathrm{NiV}$ infection will involve analysis of the Cynomolgus macaques, African green monkey and squirrel monkey genomes. Cynomolgus macaques do not develop signs of $\mathrm{NiV}$ disease while African green monkeys and squirrel monkeys are susceptible to $\mathrm{NiV}$ infection. Cynomolgus macaques are found in Southeast Asia where $\mathrm{NiV}$ is endemic and likely co-evolved with $\mathrm{NiV}$ or related henipaviruses. African green monkeys, on the other hand, are from Africa and squirrel monkeys are from South and Central America. NiV is not endemic in these places and thus these species are naive to exposure to $\mathrm{NiV}$. As DNA sequencing technology continues to improve and become cheaper, soon the genomes from these primate species will be fully sequenced and annotated and this will allow for experiments to understand the host genetics that allow some primate species to be susceptible while others are not. This understanding will offer additional human targets for therapeutic intervention.

Experiments are also underway examining nonpharmacological treatment options for treating animals infected with NiV. With high-level supportive care, such as found in a hospital intensive care unit, most patients are able to survive the respiratory component of $\mathrm{NiV}$, but the meningoencephalitic component often leads to death with many survivors having long-term neurological sequelae. The biosafety level 4 laboratory at the United States National Institute of Allergy and Infectious Diseases Integrated Research Facility now has the capacity to handle nonhuman primates in a setting with advanced medical imaging and intensive medical care [20], thus allowing for experiments examining means of decreasing morbidity and mortal- ity in $\mathrm{NiV}$ infection using methods other than novel drugs. Alternatively, there is a new ferret model with a recombinant $\mathrm{NiV}$ mutant lacking both $\mathrm{C}$ and $\mathrm{W}$ protein expression that drastically decreases the respiratory component of $\mathrm{NiV}$ disease while still allowing for neurological disease which can lead to death or survival with long-term neurological sequelae, similar to human cases [8]. This model will also allow for experiments in means of decreasing morbidity and mortality in NiV infection using similar alternative methods in laboratories not equipped with the advanced medical facilities of the Integrated Research Facility.

\section{Conclusion}

Research over the last two decades has provided insight into the mechanisms of pathogenesis and transmission of NiV. The next decade is likely to see advancement of this understanding, and, more importantly, practical applications of it in the form of vaccines for $\mathrm{NiV}$ entering human clinical trials, prevention of infection through modifying risk factors and in the development of therapeutics and techniques capable of treating infected patients to reduce morbidity and mortality.

\section{Financial \& competing interests disclosure}

The author has no relevant affiliations or financial involvement with any organization or entity with a financial interest in or financial conflict with the subject matter or materials discussed in the manuscript. This includes employment, consultancies, honoraria, stock ownership or options, expert testimony, grants or patents received or pending, or royalties.

No writing assistance was utilized in the production of this manuscript.

\section{Open access}

This work is licensed under the Creative Commons Attribution 4.0 License. To view a copy of this license, visit http://creativecommons.org/licenses/by/4.0/

\section{References}

1 Satterfield BA, Geisbert TW, Mire CE. Inhibition of the host antiviral response by Nipah virus: current understanding and future perspectives. Future Virol. 11(5), 331-344 (2016).

2 Sejvar JJ, Hossain J, Saha SK et al. Long-term neurological and functional outcome in Nipah virus infection. Ann. Neurol. 62(3), 235-242 (2007).

3 Clayton BA, Wang LF, Marsh GA. Henipaviruses: an updated review focusing on the pteropid reservoir and features of transmission. Zoonoses Public Health 60 (1), 69-83 (2012).

4 Islam MS, Sazzad HMS, Satter SM et al. Nipah virus transmission from bats to humans associated with drinking

traditional liquor made from date palm sap, Bangladesh, 2011-2014. Emerging Infect. Dis. 22(4), 664 (2016).

5 Nahar N, Sultana R, Gurley ES, Hossain MJ, Luby SP. Date palm sap collection: exploring opportunities to prevent Nipah transmission. EcoHealth 7(2), 196-203 (2010).

6 Homaira N, Rahman M, Hossain MJ et al. Nipah virus outbreak with person-to-person transmission in a district of Bangladesh, 2007. Epidemiol. Infect. 138(11), 1630-1636 (2010).

7 Satterfield BA, Cross RW, Fenton KA et al. The immunomodulating $\mathrm{V}$ and $\mathrm{W}$ proteins of Nipah virus determine disease course. Nat. Commun. 6, 7483 (2015).

8 Satterfield BA, Cross RW, Fenton KA et al. Nipah virus C and $\mathrm{W}$ proteins contribute to respiratory disease in ferrets. J. Virol. 90 (14), 6326-6343 (2016). 
9 Watkinson RE, Lee B. Nipah virus matrix protein: expert hacker of cellular machines. FEBS Lett. 590 (15), 2494-2511 (2016).

10 Escaffre O, Borisevich V, Rockx B. Pathogenesis of Hendra and Nipah virus infection in humans. J. Infect. Dev. Countries 7(4), 308-311 (2013).

11 Geisbert TW, Feldmann H, Broder CC. Animal challenge models of henipavirus infection and pathogenesis. Curr. Top. Microbiol. Immunol. 359, 153-177 (2012).

12 Mathieu C, Guillaume V, Volchkova VA et al. Nonstructural Nipah virus $C$ protein regulates both the early host proinflammatory response and viral virulence. J. Virol. 86(19), 10766-10775 (2012).

13 Mire CE, Satterfield BA, Geisbert JB et al. Pathogenic differences between Nipah virus Bangladesh and Malaysia strains in primates: implications for antibody therapy. Sci. Rep. 6, 30916 (2016).

14 Broder CC, Weir DL, Reid PA. Hendra virus and Nipah virus animal vaccines. Vaccine 34(30), 3525-3534 (2016).

15 Satterfield BA, Dawes BE, Milligan GN. Status of vaccine research and development of vaccines for Nipah virus. Vaccine 34(26), 2971-2975 (2016).
16 Coalition for Epidemic Preparedness Innovations. http://cepi.net/sites/default/files

17 Khan MS, Hossain J, Gurley ES, Nahar N, Sultana R, Luby SP. Use of infrared camera to understand bats' access to date palm sap: implications for preventing Nipah virus transmission. EcoHealth 7(4), 517-525 (2010).

18 Khan SU, Gurley ES, Hossain MJ, Nahar N, Sharker MAY, Luby SP. A randomized controlled trial of interventions to impede date palm sap contamination by bats to prevent Nipah virus transmission in Bangladesh. PLoS ONE 7(8), e42689 (2012).

19 Nahar N, Mondal UK, Sultana R et al. Piloting the use of indigenous methods to prevent Nipah virus infection by interrupting bats' access to date palm sap in Bangladesh. Health Prom. Int. 28(3), 378-386 (2013).

20 Cong Y, Lentz MR, Lara A et al. Loss in lung volume and changes in the immune response demonstrate disease progression in African green monkeys infected by smallparticle aerosol and intratracheal exposure to Nipah virus. PLoS Negl. Trop. Dis. 11(4), e0005532 (2017). 